\title{
Anthropological Bases of Formation of Moral and Legal Culture of Future Teachers
}

\author{
I. Tsaryk ${ }^{1}$ \\ ${ }^{1}$ Belarusian State Pedagogical University named after Maxim Tank.
}

\begin{abstract}
ARTICLE INFO
Keywords:

moral, law, rights and freedom, moral and legal culture, moral and legal upbringing.

ABSTRACT

In the context of anthropological understanding for mature, selfupdating personality the moral and legal culture is an essential element. Personality with the high level of the moral and legal culture is able to integrate in his mind and behaviour some moral and legal norms, to create mindset according to these norms, to express and assert himself, to strive to transform the surrounding not destroying it, it is ready to act in the framework of freedom and responsibility. High social expectations for the moral and legal upbringing of the younger generation make new demands on the teacher and it necessitates the creation of the moral and legal culture at the university education. It was developed the model of the educational process at the pedagogical university in our research.
\end{abstract}

\section{Introduction}

Transformations of society in the third millennium of one of priority tasks revealed need of education of the citizen acting as the subject of activity of the state, the moral and law. The rights and freedoms of a citizen and of a human being are approved as the supreme value in society, however these processes are not supported with appropriate level of moral and legal culture of the population.

Development of democracy inevitably leads to change of an entity of educational process in which central position is taken by the personality with the high level of the consciousness oriented to freedom of judgments and actions at simultaneous awareness of public need of following to social norms. Education of such personality in many respects depend on the teacher as it should provide professionally process of education of children and the studying youth in the spirit of requirements of the right and morals. Today the teacher owning at the high level the system of moral and legal knowledge, modern technologies and methods of education of pupils capable to assessment of pedagogical process and its results from positions of moral and legal values, understanding need of personal and professional self-development is necessary. In this regard forming of moral and legal culture of students - future teachers acquires special relevance today.

$\square$ Corresponding Author E-Mail Address: iraz@tut.by 
As the specific socially caused phenomenon which is carrying out important the socializing, humanitarian mission, such scientists as Evsikova (2007), Komarova (1998), Kononenko (2011), Larina (2008), etc. were engaged in development of teoretiko-methodological aspects of moral and legal culture. Issues of education of legal culture of students in the conditions of secondary vocational and higher education are mentioned in works Genisher (1999), Zavyalova (2007), Nikitina (2006), Nikolaeva (2005), Nuzhnova (2002), Potomakhin (2009), Rassolova (2014), etc. Researchers revealed close connection of formation of legal culture of students with moral education (Arsentyeva, 1996, Rudykh, 2002, etc.).

Directly forming of moral and legal culture of the identity of the student a number of dissertation researches is devoted to a problem. Pavlova studies pedagogical conditions of forming of moral and legal culture of students in the educational and educational environment of higher education institution (Pavlova,2014). Tsarkova stops on efficiency of development of moral and legal culture of law students (Tsarkova, 2003). In Dyachkova's research the entity and structure of moral and legal culture of the student from a position of personally oriented approach is considered and methodical ensuring this process is offered (Dyachkova, 2018). The analysis of researches on a problem is allowed to say that in modern pedagogical science and practice there is an active search of new, effective approaches to forming of moral and legal culture of students during its training in institution of higher education today.

The appeal to anthropological approach in a solution of the problem of formation of moral and legal culture of future teacher is timely as today reorientation of education from the strategy of objektocentristsky approach on anthropological is necessary, focusing on recognition of the person by the subject of legal relations, activation of his personal resources, development of responsibility, independence. At the same time, the problem of realization of anthropological approach in moral and legal education was not comprehended at the integrative level, was not considered as an imperative of personal self-development.

According to it, the purpose of our research consisted in consideration of the anthropological bases of process of forming of moral and legal culture of future teacher that demanded a research of genesis of a problem of integration of moral and legal aspects of education, definition of its entity and development of the anthropooriented model of educational process of the pedagogical university.

\section{Body}

The anthropology as science about origin and evolution of the person received a powerful boost of development thanks to rather recent opening of scientific different spheres of knowledge. Today the anthropology, culture anthropology, legal anthropology or anthropology of the right and pedagogical anthropology studying the different parties of human life caused by influence of social, culturological, legal and other factors develops philosophical. The research of a problem of formation of moral and legal culture of students demands judgment of an essence of this phenomenon in the context of anthropological understanding.

The problem of interaction of morals and the right, integration of moral and legal education always was in the center of attention of progressive thinkers. It is a subject of studying of philosophy, ethics, jurisprudence, sociology, psychology, pedagogics and other sciences. So, Hegel in the work "Legal philosophy" cites words of one of Pythagoreans: "How it is better to bring up the moral person? To make him the citizen of the state in which good laws ... dominate" (Hegel, 1990). 
The morals and the right as valuable forms of human life are the defining factors in development of a civilization and the person. The retrospective analysis of ethic and legal exercises allows to allocate three top trends in interpretation of interaction of morals and the right. Let's consider them in more detail.

The first trend is characterized by orientation to a priority of moral values in the relations of the personality and the state. According to Confucius, Democritus, Spinoza, G. Hegel, I. Kant's philosophical views as regulators of behavior of the person in society its moral qualities act. The sense of a categorical imperative of I. Kant consists in a prevalence of a debt, the obligation controlled by the highest, divine force, but not the states and laws. The bright representative of this direction in Russia is L.Tolstoy. (Valitsky, 1991).

The trend on exaggeration of a role of morals in the ratio with the right had a great influence on the nature of researches 60 - the 70th of the 20th century. Publications of those years contain not always valid conclusions about narrowing of a role of a legal factor in life of the society forming communism. The simplified understanding of the regulations on expansion of a field of activity of a moral factor enshrined in the Program of the CPSU (1961) gave the grounds to some authors to claim that the right gradually is absorbed or removed morality (Berchenko, 1966) that rules of law give way to moral standards (Khaykin, 1972).

Orientation to exaggeration of a role of the right in development of society and the public relations is characteristic of the second trend (Legalists, Platon, the Roman right, Hobbs, etc.). Since 19th century, the ideas of positive law gain development (I. Bentam, J. Mill, K. von Sawinya). According to the positivistic theory, harmony and justice of the public relations it is possible to reach through the right. In particular, the right was treated as the certain self-sufficing form defining all fields of activity of the state and the person.

The special position within this trend is taken by the founder of the psychological theory of law L.N. Petrazhitsky. In morality the imperative, that is motives of a duty is important, in the right the major role is played by attribution, that is the satisfaction moment from fulfillment of duties. It gives the basis to consider that the right role in public life is much more important than a morals role (Petrazhitsky, 2000).

The trend for consideration of the right as the defining factor of human relations and the state is brightly traced in works 20 - the 50th of the 20th century. Scientific research of that time was under the influence of installation of the "chief" lawyer of the former USSR A.Ya. Vyshinsky according to which the educational role of the right was ignored and its retaliatory, compulsory party was emphasized. The analysis of researches of the last decades focused on a right priority shows that in the conditions of the constitutional state where the right acts as the guarantor of personal freedoms, the role of his educational function amplifies. Results of the researches disclosing right value in aspect of freedom, self-determination and self-realization of the person in society are especially significant. At the same time, the right has no opportunity to regulate all types of human relations (in particular, friendship, love) and the person with itself. Recognition of a priority of the right as the external determinant defining human life in society deprives the identity of the right to be the subject which is carrying out the free choice, independently defining a measure of the responsibility (Lukasheva, 2009).

The third trend on recognition of dialectic unity of morals and the right in different options of a ratio of interests of the state and the personality, justice and the law, morality and the right, is traced in views of progressive thinkers of the different historical periods (sophists, D. Locke, Che. Montesquieu, Zh.Zh. Russo, etc.). In the Russian legal science moral values and categories in 
refraction to a perspective of the right were considered within tradition of the so-called "natural right" (Vysheslavtsev, Ilyin, Novgorodtsev, Solovyov, Chicherin, etc, 1997).

One of the first in the 20th of the 20th century in the Soviet Union the attempt to reveal the social nature and an entity of unity of morality and the right was undertaken by G. Gurvich (1924). Then in the 50th of the 20th century there were works which essence was that in historical perspective the right will be succeeded qualitatively by other norms of social regulation, however process this, deeply dialectic inherently, occurs not by weakening of a legal factor, and through its every possible development and improvement.

The modern researchers are emphasized that the morals and the right function as complete organic systems. There is a continuous interaction of morals and the right (Murashko, 2000).

Moral and law norms call special standard and organizational forms (Alekseev, 1968), "normokompleks" (Murashko, 2000), etc. Ideas of the good and evil, freedom and responsibility, justice, a debt and conscience, honor and advantage, etc. are embodied in categories and moral standards. Incorporating these categories and norms, the right "translates" them into language of the legal rights and duties. The question of interrelation of freedom and responsibility revealed Tipukhin (1997), etc. According to V.A. Oygenzikht's research, as the main regulator of behavior of the person in a coverage of moral precepts of law the conscience, a debt, honor, justice, will, freedom act (Oygenzikht, 2008). Moral and legal sense as L.S. Mamut notes, operates with such valuable categories as justice, freedom, advantage, a debt (Mamut, 2011). The justice problem as the value defining the nature of interaction of morals and the right was a subject of researches of Ekimov (2012), Yavich (1978). As the universal values and norms representing the sphere where the morals and the lawt most closely interact, researchers distinguish justice, freedom, responsibility, advantage, conscience.

The analysis of literature allows to claim that interpenetration of morals and the law is process of accumulation, addition of their potentials for the purpose of providing and protection of values, necessary for society. It is shown in any sphere of interaction of morals and the law. At the same time the complementarity of morals and the law is not manifestation of their indivisibility. These are rather mature and independent systems which work in common owing to need of an additional reinforcement of requirements of one standard and valuable system with installations another; and both the lawt, and morals do not duplicate each other. These are not identical systems, everyone has specific tools and means, the priorities (in the right - equality, legality; in morals mercy, good).

The conflict of morals and the law practically does not arise, so far as concerns human rights. The complex of the social norms of the increased importance directed to satisfaction of values of civilized activity and communication of the person consists in human rights. It has the defining standard and valuable value both for legal, and for moral systems. Therefore in modern literature of human right call an ethic and legal design, emphasizing with that coexistence of legal and ethical elements. As a matter of fact it is about special philosophy of human rights which considers interaction of morals and the aw as ethically also legally significant complex which end in itself are the person, his rights, freedom, his benefit.

The last trend most adequately reflects processes of democratization of the state, legal relationship and a humanization of the law. The dialectic unity of morals and the law reflects the fact that in real life there are no purely moral, or purely legal relations. Coverages of morals and the right are difficult to be differentiated. The law includes not only set of the legal norms recorded and authorized by the state but also covers customs, traditions, religion, the natural right, thus including also ethical standards (Lukasheva, 2008). The morals have properties of universality, 
ability to get into all spheres of public life. Moral categories act as criteria of behavior and express the valuable relation of people to all areas of their activity including to the law. Expansion of the sphere of the public relations which are in common regulated by morals and the law is reflected in the international and national legislation: contracts on protection of human rights, constitutions of the democratic states, laws and bylaws constructed on the principles of a priority of interests of the personality in public relationship.

However in many domestic researches the morals and the law are considered mainly as the external forces influencing the person i.e. from a position of objektocentristsky approach. The morals, the law and norms reflecting them act as the instruction of due or possible behavior, a lever on consciousness, mentality, will of people (Kerimov, 2005). The task of the individual comes down to so-called socialization, adaptation to a public system. Such position, according to us, ignores understanding of the personality as subject of activity, levels the value of moral selfcontrol, narrows for the personality a possibility of freedom of the moral choice of actions of own will, according to own conscience. Recognition of the person by the creator of reality, a priority of its interests in the sphere of morals and the law demands consideration of a problem from positions of its subjectivity, i.e. anthropological approach.

In modern science the theory of ethics of the law (Bukreev, Rimskaya, 1998, Gavrilova, 2018) is developed. The subject of its research approves not the law, and the human in the law, the analysis of its valuable relation to the law. The essence of this theory is that the moral and legal reality is derivative of the human, his spiritual, creative potential.

If in legal literature of last years the thought was not called in question that education of respect for the right is based on display of force of the law, inevitability of punishment, then in recent years it is claimed that between the prestige of the right connected with its retaliatory force, and a condition of crime in the state there is no direct dependence (Davydov, 1994). Therefore, the emphasis on the sanction of the law, intimidation by punishment are not productive. In this regard in science the concept of voluntary compliance with law which is under construction on the idea of integration of moral and legal education is developed.

Since 50th of the last century the new direction in domestic science - the theory of moral and legal education arises. In its development it is possible to allocate three top trends: recognition of a priority of moral education over legal, expressed in a statement that the level of moral sense, moral motivation of the personality determines the level of her legal liability; a priority of the legal aspect providing to the socialized subject perception of borders permitted by the law and definition of limits of moral; recognition of dialectic unity and interrelation of moral and legal education.

Essence of the first trend - in primacy of moral education in relation to legal (Golubeva, 1998, Apletaev, 1979). The level of moral understanding by the identity of the public relations, the higher and the level of her responsibility in performance of a moral imperative, the legal rights and duties is higher.

The second trend is that both moral, and legal education focus the person on understanding of a debt, the duties, understanding of the social importance of moral precepts of law by it for the benefit of society, about, relationship between people and ways of self-realization in surrounding life (Obukhov, 1988, Khaykin, 1972). In the course of moral and legal education of the personality judgment of moral justification of precepts of law, their expediency and value for the human is important.

The third trend is caused by actually ethical approach to an initial concept of the right (Kuznetsov, 1979, Shapiyeva, 1985, Grinkevich, 1991). In the center of attention of educational 
process the inclusiveness of morals not only in precept of law, but also in the system of legal relationship moves forward. It provides moral assessment of the legal phenomena and events, human relations, the personality and society, the personality and the state. This approach assumes and at the same time correction of moral guidelines of the personality by means of the law.

The dialectic unity of moral and legal education of the personality corresponds to the psychological mechanism of mastering of social norms of behavior by her. The universal nature of morals and ethical standards defines assessment and the relation of the human to all phenomena of reality, including to themselves and the acts. This trend most fully corresponds to the principle of integrity of process of education, failure from specialization in the directions in educational work. It is about that in complete process of education of the personality potential not only the informative party of interrelation of the morals and the law expressed in moral precepts of law but also procedural - use of forms and methods, specific to them, was used.

Directly a number of dissertation researches is devoted to a problem of moral and legal education. (Grinkevich, 1991, Ermolich, 2005, Kuznetsov, 1979, Podgorny, 1983, Tsaryk, 2003) acted. At the same time, the appeal to scientific literature allows to note that special researches on a problem of formation of moral and legal culture of students on the basis of anthropological approach in this area still are not enough.

In the context of anthropological understanding for the mature, self-updated personality moral and legal culture is a necessary component. The personality with the high level of moral and legal culture is capable to integrate in the consciousness and behavior moral and precepts of law, to form according to them smyslozhiznenny installations, to self-express and ego-trip, seeks for transformation of the environment, without destroying it, is ready to act within freedom and responsibility.

The hypothesis of a research consists that process of formation of moral and legal culture of future teacher to a context of anthropological approach is based on the basis of recognition by it of the personal importance of morals and the law when submission to the law becomes not so much external manifestation of lawful behavior, how many internal belief.

Thus, the analysis of an entity of moral and legal culture allowed to define a research position according to which priority the anthropological approach directed to recognition by the subject of the personal importance of morals and the right and their requirements acts. Within this approach the moral and legal culture of future teacher represents the integrative quality of the personality which is shown in ability to be guided by moral and legal values, pedagogical support of students in the course of its self-development and self-realization, to be guided by moral precepts of law in training and education of pupils. Such teacher is capable to implementation of the main mission assigned to him by society for education of the younger generation capable to make crucial and independent decisions, to be socialized, adapt successfully to the changing conditions, to respect the legal and ethical rules.

It is supposed that in the course of formation of moral and legal culture of students - future teachers the nature of educational process of the pedagogical university is of great importance. In research the model of educational process of the pedagogical university which is under construction on the principles of integration of legal and moral capacity of institution of higher education was developed. Legal potential consists in improvement of its regulatory legal base, and moral - in creation of conditions for fixing of moral values as bases of their cooperation, selfrealization, self-determination of students.

The model contains the ideas which define an entity and content of process of forming of moral and legal culture of future teachers. Let's characterize the called ideas. 
Idea of integration of moral and legal values. As the universal values representing the sphere where the morals and the right most closely interact the rights, freedoms and duties are selected. In the conditions of development of Bologna Process the academic rights and freedoms of students allowing to provide to each of them the broad range of opportunities of continuous education during all life, the adequate quality level of preparation depending on abilities of the student and requirements of a profession, etc. have the special importance.

The idea of updating of a moral and legal component of maintenance of subjects and educational work that assumes definition of the key moral and legal ideas, concepts, values which development promotes personal and professional formation of future teachers. Updating of a moral and legal component is provided also through selection of the corresponding content of subjects, application of the methods and forms aimed at the development in students of ability to make decisions from a position of requirements of moral precepts of law, etc.

The idea of cooperation of subjects of educational process assumes that each student and the teacher takes a subject position where there are an enthusiasm for joint creative activity and unity of interests. Development of legal relationship between all participants of educational process is provided through improvement of the regulatory legal base, fixing of moral and legal values as bases of their legal security and self-realization. Joint activity is impossible without a certain level of formation of moral and legal culture of teachers, students, the management of the university that warns the conflicts, situations of misunderstanding, violation of the rights and freedoms.

The idea of existence of personal legal space consists in creation of conditions for selfdevelopment and self-realization of the student in the conditions of educational process of the university. The personal legal space represents personal set of the rights, freedoms, the individual's duties and also recognition of individual autonomy of the personality (T.S. Dyachkova, T.N. Lovnichaya, D.V. Polezhayev, etc.). The personal legal space, in fact, is a certain legal framework of the personality and a limit of legal regulation, illegal acts violates moral standards and the rights that leads to violation of personal legal space of other individual [5].

The idea of the binarity defining that the efficiency of moral and legal education of the studying institutions of education directly depends on the level of moral and legal culture of the teacher. Only the teacher with the high level of moral and legal culture is capable to give to the student pedagogical support in process of its self-development and self-realization that demands from him experience of lawful behavior and acceptance of crucial decisions from a position of requirements of morals and the right. Realization of this idea demands search of new forms and methods to formation of moral and legal culture of students during its training in institution of higher education.

The designated ideas can be realized through change of a regulatory framework of educational process, democratization of the relations of its subjects, the statement of the academic rights and freedoms of students, development of control systems and self-government, creation of the environment of the advancing professional development.

Change of a regulatory framework of institution of higher education is carried out through inclusion of moral and legal values and norms in its Charter; Provision on student council of the university; Provision on the curator of student's group; Provision on council of prevention of offenses, etc. In these documents the rights, freedoms and duties of all subjects of educational process make a reservation.

The significant place in model of educational process of the university, belongs to student government which is under construction on the principles of morality and legitimacy and solves 
problems of inclusion of students in management of the University, formations at them personal responsibility for the made decisions. Future teachers actively, getting into gear of bodies of student government, gain experience of cooperation and legal relations.

Creation of the environment of the advancing professional development of future teachers accumulates in itself set of educational and methodical and didactic means of pedagogical training of students, connects it with real student teaching, allows to organize productive cooperation of all subjects of educational process. Process of vocational training has to be focused on formation of moral and legal culture of the student with a support on methods of contextual training during which mastering future teacher anthropological practice "... is carried out that is practice of social creation of the person who effectively adapts in society makes the contribution to social development by realization of the individual and creative potential".

\section{Conclusion}

The following provisions allowed to prove consideration of the anthropological bases of process of formation of moral and legal culture of future teachers:

- a role and the place of moral and legal culture in the vocational training of future teacher;

- a basic possibility of updating of content of educational process of the pedagogical university due to integration of moral and legal potential, democratization of the relations and cooperation of its subjects, the statement of the academic rights and freedoms of students, expansion of their duties, development of control systems and self-government, creation of the environment of the advancing professional development.

- the idea of binarity as features of vocational training of future teacher on the basis of anthropological approach defining that formation of high level of moral and legal culture of future teacher acts as a condition of moral and legal education of pupils of school.

The offered model allows to present more accurately process of formation of moral and legal culture of future teachers in educational process of the pedagogical University.

\section{References}

1. Bologna Process as way of modernization of the higher education system of Belarus / S.S. Vetokhin [etc.]; scines edition A.V. Lavrukhin. - Minsk: Medisont, 2014.

2. Bukreev, V.I. Etiks of law: from sources of ethics and the right to outlook: studies grant / V.I. Bukreev, I.N. Rimskaya. - M.: Yurayt, 1998.

3. Valitsky, A. Moral and the law in theories of the Russian liberals of the end of XIX-the beginnings of the XX century / A. Valitsky // questions of philosophies. - 1991. — No. 8. - Pp. 25-40.

4. Hegel. Legal philosophy: Соч. / G. Hegel. — G.VII. - M.-L., 1934.

5. Dyachkova, T.S. Formation of moral and legal culture of students in educational space of institution of higher education of higher education: abstract of dissertation. ... cand. of pedag. sciences: 13.00.02; Belarussian State Pedagogical University named after Maksim Tank / T. S. Dyachkova. - Minsk, 2018.

6. The concept of continuous education of children and the studying youth in Republic of Belarus: approve resolution Ministry of formation of Republic Belarus, on July 15, 2015, No. 82 // collection of normative documents. Ministry of education of Republic Belarus. - 
2015. - No. 11. - Pp. 5-23.

7. Murashko, L.O. Precept of law in the system of social norms: dissertation ... candidate of law sciences: 12.00.01. - Minsk, 2000.

8. Pavlova, M. V. Formation of moral and legal culture of students in the conditions of the educational and educational environment of higher education institution: abstract of dissertation. ... cand. of pedag. sciences: 13.00.01 / M.V. Pavlova; Mariysky State University. - Yoshkar-Ola, 2014.

9. Petrazhitsky, L.I. The theory of the law and the state in connection with the theory of morality / L. I. Petrazhitsky. - SPb.: Lan, 2000.

10. Rassolova, E. A. Formation of legal culture of professional activity of students of humanitarian institutes: abstract of dissertation. ... cand. of pedag. sciences: 13.00.08 / E. A. Rassolova. - M, 2014.

11. Rudykh, S.A. Formation of ethic and legal culture of future teacher: abstract of dissertation. ... cand. of pedag. sciences: 13.00.08 / S.A. Rudykh; The Armavir State. Pedag. In-t. Armavir, 2002.

12. Russian legal philosophy: philosophy of belief and morality: Anthology / Originator A.P. Albov, D.V. Maslennikov, A.I. Chislov, S.V. Filippova. — SPb.: ALETEYYA, 1997.

13. Tsaryk, I.A. Interaction of morals and right as basis of civil education of the personality. A. Tsaryk // Social and economic and legal researches. - 2009. - No. 2. - Pp. 65-74.

14. Tsarkova, M. V. Development of moral and legal culture of students of humanitarian institutes: abstract of dissertation. ... cand. of pedag. sciences: 13.00.01, 13.00.08 / M.V. Tsarkova. - Kirov, 2003.

15. Shapiyeva, O.G. Problems of the general theory of moral and legal education: diss. ... cand. of law sciences: 12.00.01. - L., 1985. 